\title{
From Intersex to DSD: the Disciplining of Sex Development
}

\author{
Catherine Clune-Taylor
}

\section{Introduction}

In 2003, the Intersex Society of North America announced the creation of the Disorders of Sex Development Consortium: a medical advisory board populated by experts in pediatric endocrinology, urology, general pediatrics, nursing, psychiatry, psychology and social work headed by philosopher and historian of science, Dr. Alice Dreger as project coordinator and editor in chief (Karkazis 258). This group, described as a collective of "three stakeholder groups - intersex people, parents of intersex people and clinicians" and funded by grants issued to the Intersex Society of North America to develop a new model of treatment for intersex conditions, electronically published two documents three years following their inception: one a clinical guideline for treating individuals with intersex conditions aimed at physicians and the other, a handbook for parents of affected children (Dreger and Herndon, "Progress and Politics" 206; The Clinical Guidelines; The Handbook for Parents). Shortly following the publication of these documents, the Intersex Society of North America (ISNA) founder and DSD Consortium member Cheryl Chase was invited to participate in the development of a document called the Consensus Statement of Intersex Management (Karkazis 258). This document, published on behalf of the American Lawson Pediatric Endocrine Society and the European Society for Pediatric Endocrinology in the August 2006 issue of the journal Paediatrics, announced both a 
new nomenclature and a new treatment model for those with intersex conditions. Specifically, the diagnostic labels "intersex" and "hermaphrodite" (or any of the latter's variations) would no longer be used to identify those with variations in congenital sex anatomy and would be replaced by the term "disorder of sex development" or DSD (Lee et al. 488). This special article went on to identify what it now envisioned as "optimal clinical management of individuals with DSD," outlining a new (if brief at 15 pages including appendices and references) North American and European standard of care for individuals with intersex conditions. The Clinical Guidelines and Handbook for Parents, released by the DSD Consortium, are seen by many as caching out the treatment model outlined in the Consensus Statement, though it neither formally endorses nor even mentions these documents. ${ }^{1}$ Indeed, the relationship between the three documents is neither simple nor clear, despite some overlap between individuals involved in the production of all three documents. The involvement of intersex activists in the production of the Consensus Statement has been described by some as limited and, at best, tokenistic, while others have claimed that the inclusion of clinicians in the DSD Consortium lent the group legitimacy at the price of a compromised vision (Karkazis, personal communication; Karkazis 258). ${ }^{2}$ Thus, while there is a general concordance between the treatment models outlined within the documents, there are some discrepancies that shall be noted when necessary.

Undeniably, the publication of the Handbook for Parents, the Clinical Guidelines and in particular, the Consensus Statement, constitute a watershed moment in the histories of both the medical treatment of individuals with intersex conditions and intersex activism. The first official change in the standards of clinical management of intersex conditions since the time of John Money, these documents represent both a conceptual and practical shift in medical approaches to intersex diagnoses, brought about in large part due to the work of intersex activists. Indeed, the 
Consensus Statement situates itself and the changes in nomenclature and treatment model it details as responding, at least in part, to "heightened awareness of ethical issues and patient advocacy concerns" (Lee et al. 488). Nonetheless, both these documents and the processes out of which they arose remain hotly contested, particularly among intersex activists and the conspicuously high number of feminist scholars active in the field of intersex activism. Perhaps unsurprisingly, the majority of debate has focused on the adoption of the undeniably pathologizing label "disorder of sex development." While this new terminology has apparently pleased many physicians and parents, many affected individuals and their advocates are angered by the adoption of the language of disorder, leading some to argue for alternative diagnoses that carry a "non-stigmatizing, non-correction demanding" tone, such as "variations of sex development" or “divergence of sex development” (Karkazis 259; Reis 541; Diamond and Beh). Further, for those sympathetic to the critiques of the medicalization of intersexuality and gender non-conformity in general that characterized the early work of the ISNA, its collaboration with clinicians and its hand in the adoption of DSD has come "as a betrayal and an abandonment of what they regarded as the larger goal" (Karkazis 258-59). Interestingly, many proponents of the new terminology have argued specifically for the need to "remedicalize" intersex bodies, so as to draw focus away from the rhetoric of "gender and genitals" and place it on the concrete medical needs of those with intersex conditions (Dreger and Herndon; Feder, "Imperatives of Normality"). In a 2009 issue of $G L Q$ dedicated specifically to discussion of the new terminology and model of treatment, Alice D. Dreger, April M. Herndon and Ellen K. Feder each draw both implicitly and explicitly on the work of Michel Foucault to argue in favour of the term "disorder of sex development" and further still, for the effacement of "intersex" as an identity that they see its adoption as entailing. 
Dreger and Herndon's article 'Progress and Politics in the Intersex Rights Movement: Feminist Theory in Action," argues that the intersex identity opponents wish to save is not "real," but a sexualized production of regulatory power as Foucault describes it—one that implies that as individuals, persons with intersex conditions have no clear sex or gender identity (Dreger and Herndon). Remedicalizing intersex conditions through their identification as bodily disorders "makes the phenomenon seem more manageable by being less potentially allencompassing of their identities" (Dreger and Herndon 212). ${ }^{3}$

In 'Imperatives of Normality: From 'Intersex' to 'Disorders of Sex Development'," Ellen K. Feder echoes Dreger and Herndon, arguing that by rejecting intersex identity, those with variations of congenital sex anatomy subvert the normalizing power of medicine to produce kinds of people. Remedicalizing intersex conditions, Feder asserts, renders them "disorders like any other" and in turn, makes clear the distinction between "the cultural issues of identity in which medicine has intervened and narrower matters of health," such that medicine is reoriented towards its proper subject of "human flourishing" (Feder, "Imperatives of Normality" 239). Drawing on the work of Cressida J. Heyes, Feder argues that this reorientation away from cultural/political concerns to those of health shall allow for normalization to do the positive work of enhancing a subject's capacities (Feder, "Imperatives of Normality" 239; Heyes).

Like those of Dreger, Herndon and Feder, this paper shall draw on the writings of Michel Foucault in its analysis of this new diagnostic label and treatment model, however, it will reach very different conclusions. Following an elaboration of those positions held by Dreger, Herndon and Feder, this paper will briefly outline the adoption of DSD as a diagnostic label and the new clinical model of treatment accompanying it, while engaging in its own Foucauldian analysis. Much in Foucault's work is applicable to those medical practices involved (and invested) in the 
physical and psychosocial management of individuals with intersex conditions, however, this paper shall restrict itself to two of his most well-known theories: his account of the mid-18 century transition from the bloody show sovereign power to a "micro-physics" of disciplinary power, and his work on the transformation of sexual behaviours into subject positions.

Unlike much of current literature, which begins from the nominal transition to conclusions (positive or negative) about identity, this article is concerned first and foremost with the practices of identification, acknowledging them as basic to the constitution of social/political identities. Thus it is to those practices deemed ideal by the new model of treatment, and to those reasons given as necessitating this change, that this paper shall apply these Foucauldian tools, arguing that this practical and nominal transition works to intensify, expand and legitimate medicine's power to discipline not only individuals with intersex conditions, but sexed bodies and their desires more generally. Specifically, this paper will argue that the establishment of the new treatment model expands both the number of disciplines and the number of physical elements recognized as involved in (im)proper sex development and further, that the temporalization of these elements works to establish sex development as a discipline. Sex development thus emerges as a field of power/knowledge that allows for the distribution of not just individuals with intersex conditions, but of all individuals, in relation to a norm. Further, while many see this model of treatment as finally acknowledging the calls of intersex activists for patient involvement in decision making, for the delaying of unnecessary surgical and hormonal treatment, and for urging honesty among physicians, patients and parents, I shall argue that for some these may be hollow victories, requiring that both the patient and his or her family be disciplined into the right attitudes, behaviours and responses to treatment-and that they themselves discipline others accordingly_in order to enjoy these gains. 
A note on terminology before we proceed: throughout this work I shall employ the term intersex as is coherent with a rejection of the phrase "disorder of sex development." Nonetheless, I do wish to acknowledge that important discussions regarding the use and meaning of this term are ongoing. While the arguments presented herein are both importantly related to and invested in these discussions, consideration of them is beyond the scope of this text. Thus, the use of the term here should be taken to signal a rejection of "disorder of sex development" in opposition to "intersex" rather than as a positive argument for its use.

\section{Dreger, Herndon and Feder: Progress and Politics, Imperatives of Normality}

Alice D. Dreger and April M. Herndon's article in the 2009 issue of $G L Q$ examining the transition from intersex to DSD offers "an examination of the progress made in intersex rights since 1990" as an example of "feminist theory in action," while at the same time providing an argument for the adoption of the DSD terminology (199). The authors present an overview of the history of intersex in Western medicine and of the intersex rights movement in North America beginning with the 1990 publication of Suzanne Kessler's article "The Medical Construction of Gender" in Signs. They consider what they see as the problematic identity politics of the intersex movement and present four specific claims to support their endorsement of the DSD labeling. First, they argue that while people sometimes refer to "the intersex community" as they do "the lesbian community," this is misleading. They write,

There are online virtual communities of people with intersex, but large numbers of intersex people do not live together in brick-and-mortar communities, and only occasionally do they come together for meetings that are primarily about political consciousness-raising rather than about sharing about particular medical diagnoses. (208) 
Second, they argue that some individuals with variations in congenital sex anatomy do not identify as intersex and object to the use of the term, as it sexualizes them (or their children if the objector is a parent), implies they have no clear sex or gender identity, and forces a (discursively produced) identity upon them to which they do not relate (208). Third they argue that "the question of who counts as intersex remains contentious" and that the term encompasses individuals with "a diversity of actual experiences" (209). Finally, Dreger and Herndon argue that finding a diagnostic label that clinicians could agree on was pragmatically necessary for the development of a patient-centered model of care and that this "would have been impossible without the shift of nomenclature to DSD" (211).

In the same 2009 issue of $G L Q$, Ellen K. Feder's article, "Imperatives of Normality: From 'Intersex' to 'Disorders of Sex Development'," examines "the historical convergence of the treatment of homosexuality and intersex" to argue that the contemporary association of homosexuality with intersex "risks obscuring those concerns unique to the treatment of intersex conditions and the consequences for affected individuals" (226). For Feder, it is the complicated historical relationship between the medical approaches to homosexuality and to intersex that has shaped both the problematic motivations underlying the Money protocol and "organized resistance to these practices in the intersex movement" (226). Feder believes that while "queer activism has provided not only a model of political activism but ready allies in demands for radical change in medical practice," we risk "obscuring the unique needs of those with intersex conditions" when we too closely identify their interests with those of LGBT communities (229). She refers here to needs she identifies as "those that medicine has itself ignored or marginalized in favor of a disproportionate...concern with gender and genitalia," citing the (at times, critical) endocrine needs of those with congenital adrenal hyperplasia (CAH) or hypotiuitarism (299). 
Feder sees the alliance between queer activism and intersex activism as one born from "what might be understood as a visceral sympathy" between those prey to "gender policing" (228). She writes:

That shame is so central to the "normalizing practices" that commonly characterized the stigmatization of those with atypical anatomies and those with "deviant" sexual desires alike underscores why so many people with intersex conditions and queer activists would find common cause. (228)

It is the close association between homosexuality and intersex, queer activism and intersex activism that in Feder's mind problematically contributes to the conception of an intersex identity analogous to queer or gay identity or an intersex community in the same way we think of a lesbian community.

In the second section of her article Feder employs a Foucauldian analysis to argue that the move from "intersex" to "disorder of development" normalizes those identified by the term such that it works to increase their capacities in two ways. First, she argues that the pathological label "disorder of sex development" makes intersex conditions "disorders like any other" and thereby reorients the focus of physicians to the concrete medical needs of those identified by the term and consequently away from a problematic obsession with "gender and genitalia" (238). Concentration of medical focus on the genuine health concerns of those with intersex conditions, Feder argues, promotes effective medical management of those conditions and allows those affected to live a life "as free as possible from the serious risks of the condition that would generally be taken to hamper human flourishing" (239). Drawing on Cressida Heyes' work on the positive aspects of normalizing power, she argues that in this way the pathologization of those with intersex conditions can work to enhance "capabilities in those same bodies" and thus enhance their capacities (Feder 239). Second, Feder argues that intersex identity does not exist 
but is rather the product of normalization and as such "changes the space of possibilities for personhood" (Feder 235). Thus, by rejecting the notion of intersex identity, those with intersex conditions subvert the regulatory power of identities and identification and increase their possibilities for personhood and expand their capacities to engage in different ways of life.

The fourth and final argument offered by Dreger and Herndon regarding the pragmatic necessity of adopting the DSD terminology aside, each of the arguments presented by the three authors draws on Michel Foucault's work on the discursive production of social/political identities, or rather, socially and politically important kinds of people. It is in Discipline and Punish and The History of Sexuality, Volume 1, that Foucault develops his now famous genealogy of the supercession of sovereign power by disciplines, those methods "which made possible the meticulous control of the operations of the body, which assured the constant subjection of its forces and imposed upon them a relation of docility-utility," marking the birth of "an art of the human body" (Foucault, Discipline and Punish 137). While I shall not recount the theories in full, it is worth returning to some key points before proceeding. For example, we should recall that disciplinary power works at the level of the individual, taking the processes of the body as both its proper object and its product. A "political anatomy of detail," disciplinary power measures and manages the operations of the body with increasing specificity such that it attains "an infinitesimal power over the active body" (Foucault, Discipline and Punish 139, 137). Further, disciplinary power is inextricably bound up with knowledge, producing both subjectivities and knowledge about those subjectivities that become the justification for its existence and expansion. Foucault's own classic examples of the identification of criminal and the homosexual as subjectivities show how disciplinary power works to produce both identities and a body of knowledge about the individuals identified as such. This knowledge, as evidence 
of the existence of these subjectivities, inscribes those individuals identified as such as both in need of and capable of correction, legitimating the existence, expansion and intensification of disciplinary power.

Dreger, Herndon and Feder each acknowledges that intersex identity is a product of the regulatory mechanisms of normalization, one constituted in part through the technologies distinctive to medicine. Both articles mention that prior to the technological advances that made the correction of intersex bodies possible, those with "ambiguous" sexual anatomies "lived relatively uneventful lives psychologically and socially" (Dreger and Herndon 201). The identification of individuals as intersex, or homosexual or a criminal through normalizing practices "changes the space of possibilities for personhood," and thus, as Feder argues, rejection of intersex identity allows those affected to subvert the power of normalization and to evade the regulatory aspects of identification. For this reason we should deny the existence of intersex identity and rather, identify those with congenital variation in sex anatomy as "normal persons" with a disorder "like any other" (Feder, "Imperatives of Normality" 235).

The attempt to subvert the power of normalization and the production of kinds of people through the denial of intersex identity conflates various meanings of intersex identity, and further, ultimately misunderstands the mechanisms by which normalization orchestrates this production. Each of the three authors notes that the label intersex is a highly contested term among clinicians, parents, patients, academics, advocates and activists and that this should not be surprising - indeed the word intersex is loaded with all of the baggage that accompanies any politicized identity, let alone one with so many invested parties. However, we must make a distinction between intersex as a sociopolitical identity espoused by activists or those individuals who see themselves as intersex, that is, as occupying a space between male and female, and 
those identified as intersex by institutions such that they are subject to the practices of normalization reserved for intersex bodies. For those in the latter group, whether they selfidentify with the term intersex is beside the point; that they are identified as such by those institutions in the business of identifying and managing the bodies and behaviours of individuals with intersex conditions marks them as the proper object of intervention and study. Indeed, failing to make this distinction obscures the relationship between the practices of disciplinary power and the subjectivities it gives rise to, such that it is possible to claim that the adoption of a terminology will subvert the problematic effects of normalization. Furthermore, attempting to render intersex conditions "disorders like any other," situates the management of intersex conditions further into the realm of the medico-scientific, legitimating its practices and making invisible the workings of biopower. For these reasons, it is to the practices advocated by the Consensus Statement, the Handbook for Parents and the Clinical Guidelines, as well as to the rationales they give for these practices, that I turn in order to explore my own Foucauldian consideration of the nominal and practical shift in the medical management and conceptualization of intersex conditions.

\section{Disordering Sex, Disciplining Development}

The formal origins of the official move from "intersex" (or variations of "hermaphrodite") ${ }^{4}$ to "disorder of sex development" (DSD) as the diagnostic label for those with variations in congenital sex anatomy can be traced to a conference held in Chicago, Illinois in October 2005 by the Lawson Wilkins Pediatric Endocrine Society and the European Society for Pediatric Endocrinology in Chicago October 27-31, 2005 (Dreger and Herndon; Davidson; Reis, 2007). ${ }^{5}$ Out of this conference came the Consensus Statement on Management of Intersex 
Disorders, making official the adoption of the term DSD by the American and European pediatric endocrine societies (Lee et al.). Situating itself (and the process out of which this document emerged) as responding to the progress made in "diagnosis, surgical techniques, understanding psychosocial issues, and recognizing and accepting the place of patient advocacy," the Consensus Statement gives three specific reasons as to why a universal change in nomenclature is necessary (Lee et al. 488). First, terms like “'intersex,' 'pseudohermaphroditism,' 'hermaphroditism,' 'sex reversal,' and gender-based diagnostic labels" are controversial, and "perceived as potentially pejorative by patients and can be confusing to practitioners and parents alike" (Lee et al. 488). Second, it argues that "a modern lexicon is needed to integrate progress in molecular genetic aspects of sex development" (Lee et al. 488). Finally, it suggests that due to the limited outcome data on individuals with intersex conditions, "it is essential to use precision when applying definitions and diagnostic labels" (Lee et al. 488).

While we might easily grant that patients may find these previous labels pejorative given their history, there is little explanation in either the documents produced by the DSD Consortium or the Consensus Statement as to how DSD might be a less confusing a label for both practitioners and parents. Under the new system of diagnosis, individuals with an intersex condition will be identified as having either 46 XY DSD, 46 XX DSD, ovotesticular DSD, 46 XX testicular DSD or $46 \mathrm{XY}$ complete gonadal dysgenesis, referencing the individual's complete number of chromosomes, their "sex chromosome" makeup and, in the last three cases, the gonadal tissue they possess (Lee et al. 489). Like intersex or pseudohermaphrodite, these new diagnoses are umbrella labels, capturing a plethora of more or less well-known conditions such as $\mathrm{CAH}$, complete and partial androgen insensitivity syndrome (CAIS, PAIS), 5-alpha reductase deficiency, vaginal agenesis, gonadal agensis, Turner syndrome, Klinefelter syndrome and sex 
chromosome mosaicism, among others. The health risks facing an individual with cloacal exstrophy and those facing one with CAIS are importantly different, requiring very different treatment approaches, yet both may receive the diagnosis $46 \mathrm{XY}$ DSD. ${ }^{6}$ Thus, proper medical treatment of any individual with a DSD, as with those identified as intersex or pseudohermaphrodite before them, requires diagnoses of their specific condition. Further, while each of these conditions may have effects on sex development-be it development of the sex chromosomes, gonads, reproductive ducts or genitalia, these effects are neither always visible, nor necessary. In addition, the effects these conditions have on sex development are often symptomatic rather than etiological; for example, while CAH may affect sex development (and does so in only some of those with a $\mathrm{CAH}$ diagnoses), $\mathrm{CAH}$ is a disorder of adrenal gland functioning and thus ultimately an endocrine disorder, leading one to wonder how the DSD nomenclature might be more accurate and less confusing than intersex.

What is perhaps more important to note for our current purposes is that the two further arguments offered by the Consensus Statement for the adoption of the DSD nomenclature are argued from and in the service of the advancement of medical knowledge. Both the institution of a modern lexicon "to integrate progress in molecular genetic aspects of sex development" and the use of more precise labels to improve outcome data, gesture towards a redefinition of individuals in the interest of scientific progress, and more specifically, an increase in medical knowledge of sex development (Lee et al. 488). As arguments taken on their own merit, neither is especially sound nor valid: for reasons stated previously, it is unclear how DSD is a more precise label than hermaphrodite or intersex such that it can aid in the development of an improved body of outcome data, furthermore, it is not clear how this new terminology integrates "progress in the molecular genetic aspects of sex development." In the same issue of $G L Q$ 
featuring Dreger, Herndon and Feder's articles, Vernon A. Rosario argues for an 'interactionist model of genetic sex modifiers that destabilize a binary model of sex in favour of a polymorphic and multifactorial model" called quantum sex (Rosario 269). Indeed, if progress in molecular genetics has done anything, it has overturned the binary chromosomal model of sex that defines individuals with one $\mathrm{X}$ and one $\mathrm{Y}$ chromosome as male, and those with two $\mathrm{X}$ chromosomes as female. Furthermore, the discovery of only a quarter of the 100,000 genes the Human Genome Project expected to locate, thoroughly undid any hopes of maintaining a one gene-one trait (or even one gene - one protein product) model of genetic determination. If anything, progress in molecular genetics has revealed that what makes an individual male or female is far more complicated than previously thought possible, leading Rosario to state:

I am not suggesting that sex is not primarily bimodal — with two curves corresponding to two typical functional outcomes, male and female. Indeed, intersex conditions largely reinforce this, because in most cases where there are chromosomal or genetic anomalies the result is infertility or reduced fertility. The swiftly expanding research on the molecular genetics of gonadal development and neurological sex differences is certain to increase the overlapping tails of those male and female curves. (278)

However, even this belies the true complexity of sex determination: beyond gonadal development and neurological sex differences, an individual's sex is dependent on hormone production and sensitivity, complex multi-step interaction of gene products and environmental factors, none of which are reflected within the new nomenclature. Indeed, it is altogether unclear how the new diagnostic labels, referencing the individual's total chromosome number along with the makeup of their "sex chromosomes" and gonads more precisely reflects the progress made in molecular genetics. If anything, one would think that the history of intersex conditions has already taught us that these indicators are not enough to make one male or female. 
Clinically, the Consensus Statement defines optimal care for individuals with intersex conditions as comprising the following:

1) Gender assignment must be avoided before expert evaluation in newborns

2) Evaluation and long-term management must be performed at a center with an experienced multidisciplinary team

3) All individuals should receive a gender assignment

4) Open communication with patients and families is essential, and participation in decision-making is encouraged and

5) Patient and family concerns should be respected and addressed in strict confidence. (Lee et al. 490)

Of the multidisciplinary team it recommends treat all individuals with DSDs, the Consensus

Statement states this team should ideally include "pediatric subspecialists in endocrinology, surgery and/or urology, psychology/psychiatry, gynecology, genetics, neonatology, and if available, social work, nursing and medical ethics," implicating the fields covered by all these disciplines as involved in (im)proper sexual development (Lee et al. 490). The DSD Consortium's documents outline a similar clinical scenario as ideal, advocating a

patient-centered, multidisciplinary team approach to caring for individuals with variations in congenital sex anatomy-with teams ideally consisting of members from the following disciplines: child psychology/psychiatry, genetic counseling, gynecology, nursing, pediatric endocrinology, pediatric urology, social work and 'others as needed.' (Clinical Guidelines 10)

Like the Consensus Statement, the Clinical Guidelines offers its own, more detailed set of principles as necessarily comprising patient-centered care for DSDs;

1) Provision of medical and surgical care when dealing with a complication that represents a real and present threat to the patient's physical well-being

2) Recognition of variations in "normality" that entails care providers not seek to force the patient into a social norm that may harm the patient

3) Minimization of the potential for patients and families to feel ashamed, stigmatized or overly obsessed with genital appearance

4) Delaying elective surgical and hormonal treatments until the patient can actively participate in decision making

5) Respecting parents by addressing their concerns and distress empathetically, honestly and directly 
6) Directly addressing the patient's psychosocial distress

7) Always telling the truth to the family and the patient (Clinical Guidelines 34)

Though the management team recommended by DSD Consortium and the Consensus Statement are similar, important differences exist between the principles they identify as defining optimal care, the most glaring of which are their positions on the timing and necessity of surgical and hormonal treatment. While the DSD Consortium advocates delaying all medically unnecessary surgical and hormonal treatment until the patient can actively participate in decision making (presumably at the onset of puberty), the Consensus Statement continues to advocate early surgical and hormonal management in "cases of severe virilization," specifically those identified as stage III-V on the Prader scale of genital virilization (Lee et al. 491). Due in differing parts to the work of intersex activists, the very public debates in recent years over genital surgery and a new wave of biological determinism flourishing within medical circles regarding the effect of in utero adrogen exposure on brain structure, the Consensus Statement presents a more conservative approach to the surgical management of individuals with intersex conditions than previous models; nonetheless, the wisdom that early, non-medically necessary genital surgery is part of optimal care remains fairly entrenched within the medical community. Katrina Karkazis writes:

Many of the clinicians I interviewed saw early genital surgery as necessary, most surgical articles take for granted that surgery will be performed (and hence simply describe how to do it) [and] opinions at professional meetings appear to agree that surgery still makes for good care. (134)

Thus, an ambivalence with regards to genital surgery is evident in the section of the Consensus Statement devoted to the topic, where despite recommending non-medically necessary surgery in the first year of life for those with "severe virilization," the authors acknowledge a general lack 
of outcome data on genital surgery (regarding both cosmetic appearance and sexual function), that orgasmic function may be harmed by surgery and that there is a lack of systematic evidence for the belief that early cosmetic surgery "relieves parental distress and improves attachment between the child and the parents (Karkazis 134; Lee et al. 491). Similar to the rationales given for the adoption of the DSD nomenclature discussed above, rationales given for unnecessary early genital surgery, both by clinicians interviewed by Karkazis and by the authors of the Consensus Statement, are medico-scientific in nature: for example the Consensus Statement cites guidelines on the timing of genital surgery set forth by the American Academy of Pediatrics and the beneficial effects of estrogen on tissue in early infancy (Lee et al. 492). Thus, medical knowledge about the body of the individual with an intersex condition gained through intervention upon it comes to justify further intervention.

Interestingly, despite its concern for precision and accuracy, the Consensus Statement itself fails to offer a specific definition for sex development (or disorder of sex development). However, the Handbook for Parents offers definitions for both, defining sex development first as the term for

... the step-by-step changes that relate to the biological (physical) features of a person's sex. The development of sex begins at conception with the combining of sex chromosomes from the mother's egg and the father's sperm. Sex development continues in the womb with the prenatal development of the internal sex organs (including the gonads) and the external sex organs (like the penis, clitoris, labia, and scrotum). For most people, sex development continues naturally little by little through all stages of life, including most noticeably at puberty (which brings many changes including altered sexual arousability, fat distribution, voice pitch, hairline, pubic, underarm, and body hair, genital and nipple appearance, breast development, skin oil and texture, and body odor) and at menopause. (119)

In contrast to this very detailed definition of sex development, "disorder of sex development" is vaguely defined by the Handbook as "a less common path of sex development" 
(119). ${ }^{7}$ This expansive list of elements involved in the sex development mirrors the extensive number of sub-specialties represented in the multi-disciplinary teams recommended by all three documents. The inclusion of each of these elements in the definition of sex development offers them up to the normalizing judgment of disciplinary power, marking each as indicative of (im)proper sex development and thus worthy of monitoring and management. The focus on "gender and genitals" that Dreger, Herndon and Feder lament is thus replaced with an expanded focus on any and all characters related to sex development, including gender and genitals. Temporalization of the "natural" development of these traits identifies a specific ideal trajectory for the maturation of those physical and psychological traits associated with sex development over time. The study and treatment of those with disordered sex development aids in the production of a normalized trajectory of sex development, establishing an internally defined system of meaning which Foucault sees as key to the function of normalization. Furthermore, the normalization of a specific, idealized trajectory of sex development allows for the ranking of all individuals in relation to the norm, expanding medicine's authority over sex development to include those identified as normal in addition to those identified as abnormal. It is quite likely that as more and more people become the proper objects of medical surveillance, a number of those who would not have been identified by the term intersex may be identified as nonetheless having a disorder of sex development. ${ }^{8}$ Increasing the number of traits that mark a person as normal only ensures that more and more people will fail the increasingly stringent criteria and find themselves marked as abnormal and in need of "management." All of this contributes to the development of sex development as a discipline within medicine, one whose goal is not just the coherence of sex and gender or sex and sexuality, but of any and all traits linked to sex development. 
On the surface, this new treatment model includes practical changes for which intersex activists have long advocated, such as emphasizing the importance of honesty between physicians and parents and between parents and children regarding diagnosis, prognosis and treatment options, involving parents and patients in the process of making decisions about treatment and delaying non-medically necessary surgical procedures until the patient themselves can make an informed decision. Indeed, many have highlighted the emphasis within the new treatment model on providing psychosocial support to patients and families, as well as the right of both to informed consent as positive additions - ones that indeed may confer capacities in the way Ellen Feder suggests in "Imperatives of Normality." Feder is quite right to draw our attention to the oft-overlooked positive, capacity building aspect of disciplinary power; indeed, disciplinary power is neither inherently positive nor negative and much of the daily disciplining of ourselves and others we engage in would undoubtedly be described as positive, if not necessary for the proper functioning of society (e.g. it is undeniably a good thing that we discipline ourselves such that we do not rape, steal from or kill others). ${ }^{9}$ However, that many of these practical changes are contingent on the receptivity of families and children to the management process, instituting a system of rewards and punishments, should make anyone employing Foucauldian methods suspicious. Whether a disciplinary practice is positive or negative, that is, generally capacity-conferring or docility-inducing can only be settled via assessment of effects of the practice. The remainder of this paper shall examine some of those disciplinary practices outlined within the new treatment model in order to consider whether they indeed confer capacities or induce docility.

As previously mentioned, although the new clinical model for individuals with intersex conditions depicts clinical management as a collaborative effort between physicians, patients and 
parents, the Clinical Guidelines nonetheless prescribes very specific behaviours and scripts physicians should adhere to in order to guide parents (and patients) to ensure that they not only make the right decisions, but that they also exhibit the correct "attitudes" towards these decisions. ${ }^{6}$ Much of the Clinical Guidelines focuses on the importance of modeling correct attitudes and behaviour towards the child, and ensuring families are both receptive to and mimic these attitudes and behaviours. For example, the Clinical Guidelines stresses that when representatives of the clinical team examine the infant, they "model calm, reassuring openness and valuing of the child" (17). It continues:

This can be furthered by speaking gently to the baby using his or her name (if one has been given) or by using gender-neutral language. Phrases like "you're a good baby," "you're doing so well, little one" or "almost done now, sweet baby" promote connectedness to the baby during the exam, which is reassuring and instructive to parents. (17; my emphasis)

Following any examination, parents are to be encouraged to dress and hold the child by both physicians and the team liaison, and to "perform any other activities that promote a sense of normalcy and bonding" (18). Physicians, here in the role of instructors, are charged with teaching parents accepting behaviours and attitudes towards their child who are in turn called upon to laterally discipline and surveil the attitudes, behaviours and responses of others. To this end, the Handbook for Parents offers scripts, laden with clinical language and statistics, for family members to use with others. For example, in the section titled "What to Tell your Friends and Family in General," the Handbook warns that "When you explain your child's DSD, you may sometimes be met with family members and friends who look shocked and say things like, 'I don't understand. Is your child a boy or a girl?'”. As a response, it offers that you may want to say "sometimes babies are born with a body type that is not either the average male or female. This is a variation that happens about one in every 1500 births"” (40). These scripts reassure 
others and normalize the child with an intersex condition by appealing to medical authority and downplaying the risk of gender dissatisfaction, acknowledged within the Consensus Statement as occurring more frequently in those with intersex conditions than in the general population. Parents are advised to respond to those who exhibit concern that the child might have received the incorrect gender assignment with something like the following: "'In our daughter Sue's case, we figured out with our doctors that Sue should be raised as a girl, since most children with Sue's condition tend to follow along with that gender"' (40). The Handbook continues by suggesting that if a family member then asks, "What if Sue turns out not to be a girl? What if she decides she is a boy?"', that parents explain to their family member that there is a small chance that any child "“even a child without a DSD, will change gender assignment, but it is pretty rare" (40). It counsels that parents might want to add that they "love Sue just as she is" and that they hope "“[you] will feel the same way"” (40).

The emphasis within the Clinical Guidelines on fostering a loving, accepting attitude within a family towards a child with an intersex condition is undoubtedly a positive feature in this new treatment model, particularly given the legacy of practices within medicine constituting intersex bodies as shameful secrets. Moreover, any practice that alleviates the stigma of having a child with an intersex condition such that affected parents and children might have more honest, loving relationships undoubtedly confers capacities to and enriches the lives of all parties. However, that the scripts appeal to medical authority and falsely represent the possibility of gender dissatisfaction may detract from the positive effects of these practices of discipline. Appealing to medical authority suggests that all individuals possess a true and knowable sex, of which medicine is the ultimate arbiter. Further, the misrepresentation of the occurrence of gender dissatisfaction in individuals with intersex conditions may provide families, friends and affected 
individuals with unrealistic expectations regarding their future. The confidence these scripts place in the judgments of medical practitioners and their misrepresentation of the possibility of future gender dissatisfaction function to individualize the gender dissatisfaction of any particular person with an intersex condition, such that their experience signifies their (and their parents') personal failure to instantiate the norm rather than the falsity of the norm.

We will recall from Foucault that, by way of examination and normalizing judgment, the performance of those subjected to disciplinary power are evaluated and subsequently rewarded or correctively punished. So too are rewards and punishments built into the disciplinary practices outlined in the new treatment model for individuals with intersex conditions. For example, the failure of family members to exhibit proper behavior or to display the right attitude towards their child may have consequences not only for the family, but for the child's gender assignment as well. To this end, the Clinical Guidelines suggests that

the psychiatrist or psychologist on the team may evaluate the care givers in terms of their education, cognitive capacity, coping skills etc. as relevant to their ability to understand the DSD and to nurture a child with a DSD. Such factors, may in some cases, have bearing on the gender assignment recommended by the team. (25)

Furthermore, the individual with the intersex condition must exhibit appropriate attitudes and behaviours as they develop so as to be able to continue with this development. Indeed, while patient involvement in decision making is emphasized within the new treatment model, the model also provides avenues through which involvement can be denied and by which sex development can be arrested altogether. The Clinical Guidelines states that for any child with an intersex condition, "a formal assessment of the child's cognitive status by a child psychologist or psychiatrist can assist in determining the extent to which the child is capable of participating in the decision making process" (29). Further, it suggests that children approaching puberty who do 
not display the correct attitude towards treatment or who fail to express a singular gender identity have their sex development chemically arrested, stating that in these cases "leuprolide (marketed as Lupron) may be used to chemically delay puberty while psychologists and psychiatrists help the child explore feelings and options" (26). It is difficult to imagine any arguments that could justify the unrequested arrest of an individual's sex development. Furthermore, this practice belies the complexity of gender and the fact that many individuals without intersex conditions fail to express or identify with a singular gender identity. The sanctioning of non-medically necessary intervention into an individual's biological and psychological development renders the gendered body and mind literally malleable, docile and primed for correction.

\section{Conclusions}

In Discipline and Punish, Michel Foucault writes of the production of subjectivities by way of the practices of disciplinary power, a form of coercion that established in the body "the constricting link between an increased aptitude and an increased domination" (138). Acknowledging the primacy of the practices of disciplinary power in the constitution of subjectivities, I have argued that the new diagnostic label and treatment model for those with intersex conditions is not the progressive move some interlocutors have represented it as, but rather continues to participate in, and in some ways expand, medical disciplining of sexed bodies and their desires. Subversion of "intersex identity" is hopeless when the practices of domination remain, and furthermore, the biopolitically empty label "disorder of sex development" belies the sociopolitical investments of the practices targeting individuals labeled as such. Moreover, the expanded definition of sex development established within the new treatment model bolsters the establishment of sex development as a discipline within medical practice-one which produces a 
normalized trajectory of sex development to which we might all be compared, and against which we might all be corrected. We must look to the effects of a disciplinary practice in order to identify it as conferring capacities or inducing docility. With this in mind, I have examined some of those practices outlined within the Consensus Statement, the Handbook for Parents and the Clinical Guidelines, arguing that while some of its management recommendations positively discipline, others do so in a negative, docility-inducing way.

\section{Notes}

${ }^{1}$ It is important to note that clinicians are not obligated to abide by the standards outlined in all three of these documents (and in particular those documents produced by the DSD Consortium). As with any instituted body of professionals, individuals are called upon to ensure colleagues behave in accordance with standard codes of practice, however there is no regulatory body to enforce or demand adherence to this new model of treatment.

${ }^{2}$ The Consortium's relationship to the ISNA (and the presence of many prominent ISNA members in the Consortium), as well as its recommendations have been criticized by intersex activists, feminist scholars and members of the Consortium itself. Several months after the publication of the DSD Consortium's handbooks, three members of the consortium asked that a one-sentence disclaimer be included "noting that though they support the documents, they do not support the term [DSD]" (Dreger and Herndon 212).

${ }^{3}$ One might wonder whether the "phenomenon" Dreger and Herndon are referring to here is the phenomenological experience of having varied or "ambiguous" genitals or the phenomenon of being taken up by medicine as having pathological genitals in need of monitoring and correction (assuming those experiences can be disentangled).

${ }^{4}$ While the term intersex has been in use since the mid twentieth century and adopted by activists and academics in the late 1980s/early 1990s as an alternative to the historically stigmatizing "hermaphrodite," "intersex" was never formally adopted by the medical community (Feder "Normalizing Medicine"; Reis). Those with variations of congenital sex anatomy continued to receive diagnoses such as "male pseudohermaphrodite" or "true hermaphrodite" (ostensibly) until the adoption of "disorder of sex development" in 2006. For a historical summary of the nomenclature, see Feder and Karkazis, "What's in a Name?".

${ }^{5}$ This highly influential conference aimed at establishing what medical identification was in the best interest of those with intersex conditions included only two intersex adults among its participants (Cheryl Chase of ISNA and Barbara Thomas of the German group XY-Frauen) and 
no parents of affected children. The majority of the "50 invited international experts in the field" were physicians (Reis 538).

${ }^{6}$ Cloacal exstrophy is a rare severe birth defect of the exstrophy-epispadias complex which is not considered an intersex condition per se, yet nonetheless identified with intersex conditions (and now as a disorder of sex development) as individuals with cloacal exstrophy are treated according to the treatment guidelines for individuals with intersex conditions. The lower abdominal organs of individuals with cloacal exstrophy, such as a bladder and intestines, are often not sealed within the abdominal wall such that they are exposed at birth. Genitalia is often also affected such that males many have shortened or split penises and females split clitorises, two vaginal openings and sealed anuses. For more on cloacal exstrophy see Karkazis (77-80; 293).

${ }^{7}$ It is interesting to note that the companion publication to the Handbook for Parents aimed at physicians, titled Clinical Guidelines for the Management of Disorders of Sex Development in Childhood does not define disorders of sex development (or sex development) in this way. Rather they define DSDs in opposition to the "imprecision" of "intersex" as conditions involving "anomalies of the sex chromosomes, the gonads, the reproductive ducts and the genitalia" and give a list of the various established medical diagnoses that fall under this broad category (e.g. Turner Syndrome, Klinefelter Syndrome, congenital adrenal hyperplasia, complete androgen insensitivity, etc.) (Clinical Guidelines 2). One can't help but wonder what the difference in terms of precision is between DSD and intersex, as they both seem to diagnostically work as umbrella terms for a list of more specific diagnoses.

${ }^{8}$ For example, an increasing number of women are diagnosed as suffering from "female sexual dysfunction" and prescribed medication due to low libido. Such diagnoses appeal to an idealized trajectory of sex development that goes beyond the simple coherence of "gender and genitals," marking the formally personal issue of libido as a legitimate object for medical surveillance and management. I see this as but a part of the larger expansion of medicine's authority over sex development (and all aspects of human life that could fall under this umbrella term).

${ }^{9}$ Thank you to Chloë Taylor for encouraging me to be more clear on this point.

\section{Works Cited}

“About Us.” Accord Alliance. Accord Alliance 2010. Web. 11 June 2010.

Consortium on the Management of Disorders of Sex Development. Clinical Guidelines for the Management of Disorders of Sex Development in Childhood. N.p. 2006. Web. http://www.dsdguidelines.org/files/clinical.pdf Accessed 13 December 2010 
Consortium on the Management of Disorders of Sex Development. Handbook for Parents. N.p. 2006. http://www.dsdguidelines.org/files/parents.pdf Accessed 13 December 2010

Davidson, R. J. 'DSD debates: social movement organizations' framing disputes surrounding the term 'disorders of sex development'." Liminalis: Journal for Sex/Gender Empancipation and Resistance. http://www.hawaii.edu/PCSS/biblio/articles/2005to2009/2006-variations.html Accessed 13 December 2010

Diamond, M., and H.G. Beh. "Variations of sex development instead of disorders of sex development.” N.p. 2006.. http://www.hawaii.edu/PCSS/biblio/articles/2005to2009/2006-variations.html Accessed 13 December 2010

Dreger, A.D. and A.M. Herndon. "Progress and Politics in the Intersex Rights Movement: Feminist Theory in Action." GLQ: A Journal of Lesbian and Gay Studies 15.2 (2009):199-224.

Feder, E. K. and K. Karkazis "What's in a Name?: The Controversy over 'Disorders of Sex Development'." The Hastings Center Report 38.5 (2008): 3336.

Feder, E.K. 'Normalizing Medicine: Between 'Intersexuals' and Individuals with 'Disorders of Sex Development'.” Health Care Anal 17 (2009): 134-43.

—. "Imperatives of Normality: From 'Intersex' to 'Disorders of Sex Development'." GLQ: A Journal of Lesbian and Gay Studies 15.2 (2009): 22547.

Foucault, M. Discipline and Punish: The Birth of the Prison. New York : Vintage, 1979.

—. The History of Sexuality, Volume 1 . New York: Vintage, 1980.

Heyes, C. Self-Transformations: Foucault, Ethics and Normalized Bodies. New York: Oxford UP, 2007.

Lee. P.A. et al. "Consensus Statement on Management of Intersex Disorders." Pediatrics 118 (2006): e488-e500.

Karkazis, K. Fixing Sex: Intersex, Medical Authority and Lived Experience. Durham: Duke UP, 2008. 
Reis, E. "Divergence or Disorder?: The Politics of Naming Intersex." Perspectives in Biology and Medicine 50.4 (2007): 535- 543.

Rosario, V.A. "Quantum Sex: Intersex and the Molecular Deconstruction of Sex.” GLQ: A Journal of Lesbian and Gay Studies 15.2 (2009): 267-84. 